\title{
Newly Arrived South Asian Students' Experience with the Canadian Healthcare System
}

\author{
Inderpreet Kaur Khunkhun $^{\mathrm{a}^{*}}$ and Bonnie Fournier ${ }^{\mathrm{a}}$ \\ ${ }^{a}$ Thompson Rivers University, Kamloops, Canada \\ *Correspondence: inderpreet2005_123@hotmail.com
}

\begin{abstract}
In this article, we report on the experiences of newly arrived South Asian international students (undergraduate and graduate levels) with accessing healthcare services in a small town setting in British Columbia, Canada. The objective of the study was to better understand the barriers and facilitators of accessing healthcare services. We used a qualitative design with an exploratory approach and conducted 8 semi-structured interviews with South Asians students that had newly arrived in the city of Kamloops and had been enrolled at Thompson Rivers University (TRU) for less than 12 months. Findings included barriers such as needing more information during on campus orientation, inefficiencies of the healthcare system, and accessing healthcare service. Facilitators of accessing healthcare services included attending campus orientation, having a curiosity, and a social support system. These findings provide new knowledge regarding the barriers and facilitators of accessing healthcare in Canada. In order to better meet the needs of international students programs and services must be tailored to this unique group of students.
\end{abstract}

Keywords: Canada, healthcare system, international students, small town, South Asian students

\section{INTRODUCTION}

According to the 2016 Census, approximately 21.9 percent of the Canadian population was composed of foreign born immigrants from many parts of the world (Statistics Canada, 2017). Additionally, 1 in 5 people in Canada are immigrants ("people born outside of Canada") (Immigration, Refugees and Citizenship Canada, 2019, p. 5). Furthermore, a stable population is needed to maintain a low dependency ratio, as this indicates there are sufficient working-aged populations (20-64 years) who can support the dependent population (0-14 years and over 65 years) (Statistics Canada, 2016). Thus, in Canada, as the dependency ratio increases and fertility rates continue to stay below replacement levels, immgration opens the opportunity for support in this ageing Canadian population (Beaujot, 2003). Immigration is important as it not only assists with the country's demographics but also allows for an increase in the economy, the diversity and cultural richness of Canada (Beaujot, 2003; Citizenship and Immigration Canada, 2013).

In 2017, Immigration, Refugees and Citizenship Canada (2019) reported over 317, 328 study permits were issued to international students and as of December 31, 2018, that figure has increased to 572,415 (ICEF Monitor, 2019) - a 45 percent increase from one year to another. International students contribute $\$ 12$ billion to Canada's GDP and support 158,300 jobs (Global Affairs Canada, 2018). The Canadian Bureau for International Education (2018) reports that 51 percent of international students plan to become permanent residents of the country. Therefore, understanding international students' needs around

Received March 31, 2020; revised April 28, 2020; August 1, 2020; accepted September 14, 2020; electronically published May 1, 2021

Journal of Comparative \& International Higher Education

May, 2021, Vol. 13, No. 2, pp. 53-64.

DOI: $10.32674 /$ jcihe.v13i2.2138

(C) 2021 Journal of Comparative \& International Higher Education. All rights reserved. 
navigating the Canadian healthcare system is important as they have a significant impact on the Canadian economy in supporting jobs, producing revenue and in improving our demographics.

\section{New Immigrant Challenges}

At the time of arrival in Canada, immigrant's rate their health status as high, however, over time this healthy immigrant effect subsequently declines (Newbold, 2005). The healthy immigrant effect describes the health status of a newly arrived immigrant when their health is higher, but subsequently declines over time (Beiser, 2005; Newbold, 2005). Beiser (2005) explains that the health of immigrants declines as they try to converge towards the social and environmental norms of the country of settlement often adopting habits such as smoking and unhealthy eating. As a new immigrant, navigating the healthcare system, several challenges arise. These challenges relate to communication barriers related to speaking another language, lack of interpreters, socioeconomic barriers such as not being able to take time off work to visit a doctor, or lack of social support (Higginbottom \& Safipour, 2015; Lum et. al, 2016). Furthermore, the Mental Health Commission of Canada (2019) demonstrated how the social determinants of health, like language, income, education, and discrimination all play major roles for immigrants in being able to access healthcare services. In addition to understanding the barriers, researchers also discuss several facilitators like social support networks, cultural organizations and their accessibility to the certain healthcare services, like having a family doctor, as key factors (Lum et al., 2016; Straiton \& Myhre, 2017). While there is a growing body of research exploring these barriers for immigrants in general, very little is understood about the experience of international students regarding accessing health care services while being a student at a Canadian University.

\section{The Experience of International Students}

Existing literature about new immigrants focus on various issues, like healthcare, language, education, and housing. Issues concerning international students are almost absent from the discussion. The published studies that do exist highlight international students' negative experiences around housing, finances, cultural shock, and the stress of being in a foreign country (Akhtar \& Kroner-Herwig, 2015; Calder et al., 2016; Presbitero 2016). Furthermore, a study conducted at TRU, where the current study takes place, explored female international student's experiences with the healthcare system (Burgess et al., 2016). This study highlighted struggles that women from many different countries face including trying to stay healthy, problems in knowledge translation, social support and more (Burgess et al., 2016). While having a broad understanding of the issues that female international students encounter with the healthcare system, there is still much variation within this population. It is difficult to generalize the findings from these types of studies to all international students. Therefore, we decided to narrow the focus to explore the experiences of newly arrived South Asian students in order to broaden the knowledge within this area of study. Therefore the focus of this research was to understand the experiences of newly arrived South Asian students at TRU regarding access to healthcare services in Kamloops, British Columbia.

\section{Context}

TRU is situated in a small town called Kamloops in the province of British Columbia, Canada. The total student population on campus at TRU during 2017-18 was 15, 622, of those, 11,461 were domestic students and 4,161 were international students (Integrated Planning and Effectiveness, 2018). According to the TRU's factbook for 2017-2018, almost 50 percent of the international students are from India, whereas students from other countries range from 1-3 percent (Integrated Planning and Effectiveness, 2018). 
Therefore, studying the needs of South Asian students would be meaningful for the university, educational specialists, healthcare practitioners and others.

When newly arrived international students come to the University's campus for the first time, they attend a week-long orientation before the start of a new semester. During orientation students are provided with information about the Kamloops, TRU and learn practical information such as local banking, obtaining a cell phone, available shopping and accommodation. Many businesses and vendors from Kamloops are part of orientation and provide information about their services as well. Students also learn about the International Student Advisory (ISA) group, who are a diverse group of members that assist students in a variety of topics, like personal counselling, housing, settlement services and much more (Thompson Rivers University, 2019). Furthermore before arriving in Canada or during their program, students can book an appointment with any of the ISA members (Thompson Rivers University, 2019).

When international students first come to Canada for University such as TRU, they are automatically enrolled in a private insurance called "GuardMe" for the first three months (Thompson Rivers University, 2018). During orientation, one full day is dedicated to introducing students to the government funded insurance called medical services plan (MSP). Student can then choose to stay with the private insurance plan or ISA members will assist the new students in transitioning to MSP. Either way, students must be enrolled in a medical insurance plan that covers them for the duration of their stay in Canada. Another healthcare related event during orientation is the cultural sessions, where throughout the week, these sessions are conducted in the students' primary language. During a cultural session, information regarding where the hospital is, what to do in an emergent situation, and the location of the walk-in clinics, are shared with students. Additionally, information regarding maintaining student's mental health is also briefly shared. If any international student misses orientation week, or misses the MSP sign-up session or their cultural session, they are able to make an appointment with the ISA members, who then provides a one-onone session with the student, throughout the year.

\section{MATERIALS AND METHODS}

A qualitative design with an exploratory approach was the methodology for the study to answer the research question - what is the experience of newly arrived South Asian students with accessing healthcare services? The study was approved by TRU Research Ethics Board. South Asian students were contacted and recruited through the TRU World International Student Services. Eight face-to-face semi-structured interviews were conducted for approximately 30-60 minutes. Due to funding constraints on time, we were only able to gather eight participants for this study. These interviews were held at a place of convenience for the participants, which was usually on campus. The interviews were digitally recorded and transcribed verbatim for data analysis. Specifically the questions asked in the interview were related to the participants' experience around the accessibility of healthcare services, the barriers and facilitators of accessing health care services and their previous and current knowledge around the healthcare services in Kamloops. The interviews with each of the participants ended when participants were unable to share any new experiences regarding healthcare. At the end of the interview, the participants were given a $\$ 20$ gift card as an acknowledgement for their participation.

\section{Data Analysis}

The data collected was analyzed using the thematic analysis approach. Thematic analysis is a coding process that identifies themes or patterns presented in the data (Maguire \& Delahunt, 2017). Braun and 
Clarke (2006) six-phase framework was utilized for coding the data. The six steps are (1) become familiar with the data, (2) generate initial codes, (3) search for themes, (4) review themes, (5) define themes, (6) write-up. This approach to data analysis is not tied to a particular theoretical framework, and it does not come with methodological stipulations about, for example, how to sample, or to collect data. We engaged with the data using a semantic focus - meaning that we coded on explicitly-stated ideas, concepts, meanings, experiences, etc. stated by the students. For example, students would report their answers to the interview questions and we developed a theme that connected each students' answers from that specific question.

Familiarizing occurred from reading and re-reading the transcripts, making notes about interesting statements, and constantly asking what does this mean? Coding occurred to identify and label interesting aspects in the data at the semantic level. The dataset was reviewed twice during the coding process. Once the codes were generated, they were organized into higher level patterns which resulted in the current reported themes. For example - by rereading each participant's transcript, codes that were similar were drawn, and from there specific themes were generated (See Figure 1). Themes were organized using the NVivo 12 software. Saturation was met when no new themes could be developed by the researcher. Once the themes were reviewed and defined, the results revealed significant information regarding South Asian student's experience with navigating the Canadian healthcare system.

\section{Figure 1}

Coding / Theme Tree

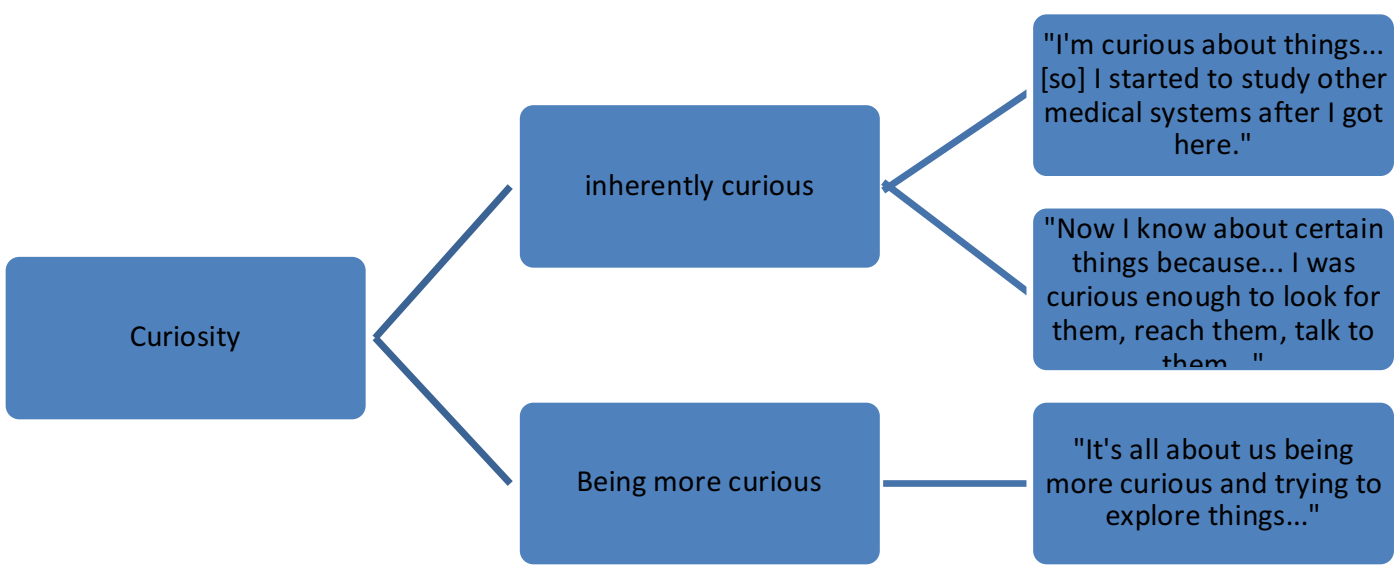

\section{Participants}

Recruitment criteria included students from South Asia and enrolment in an undergraduate or graduate level program at TRU. Furthermore, the participants needed to have been in Canada for 12 months or less. Participants included students from various regions in India. Out of the eight participants, two of them were female and six were male. Due to funding restrictions related to time, the researchers were unable to avoid the unintended gender imbalance. All of the participant's native language was Hindi, which is also the national language of India. The age range of the students was 19-25 years old.

\section{Results}

The results have been organized around the two main foci for the study - facilitators and barriers. A number of themes were developed related to facilitators and barriers of accessing healthcare. Facilitators 
included campus orientation, curiosity, and social support system. Barriers included more information needed at orientation, inefficiency of services, and a lack of understanding of the government sponsored medical services plan.

\section{Facilitators}

\section{Campus Orientation}

The TRU orientation was seen as one of the facilitators for most students who were interviewed. While not initially stated during the interview, when prompted, stated "[at] orientation we are actually told about GuardMe and to register for MSP." There was diversity in the answers regarding how students felt about orientation. Four students felt that the international students' orientation was a helpful facilitator as one stated "ISA educated me [on] how healthcare works or how the insurance works, that was helpful as I had no idea." Another student stated "as you come to orientation, you come to know that you are supported by GuardMe for three months and then...you need to apply for MSP at the same orientation." Furthermore, another student reflected that "orientation explained what are some things that we should do for example, if there is an emergency, how to call the ambulance and that the Royal Inland Hospital has an emergency room". Generally, most students interviewed found orientation was helpful in pointing them in the direction of insurance and how it works in British Columbia.

\section{Curiosity}

Another interesting facilitator was the student's own curiosity in seeking information. When asked what was helpful in understanding the healthcare system in Kamloops, a participant specified "to make this very simple, I am curious about things and I want to save money ... back in India, I was more focused on other things but after getting here, I started to pay money and wanted to learn how I am putting my money or what I am putting my money towards." Another student reflected that "I know certain things [about the medical system] because I am more involved with ISA and more and more with.... clubs because I was curious enough to look for them, reach them, talk to them and because of ISA, I was able to do this interview." Overall these students demonstrated that their curiosity was what drove them to understand more and to navigate the healthcare system in Canada.

\section{Social Support System}

Students also felt that having a social support system, whether it be their family, peers, or even campus members like the ISA members, were helpful in navigating the healthcare system. One participant stated "I do get information from campus from making friends who are in nursing and stuff [healthcare field]. Another participant stated that ISA was helpful in answering their questions as they "just went in for more information" regarding medical insurance. Furthermore, a different participant reflected that having friends on campus was helpful for them in navigating the system as they stated "now I know about certain things because now I'm more involved with ISA and more and more with the Intercultural club, and humans of TRU...." Students that would meet with their ISA members or who had peers on campus, felt that they were useful in helping them in navigating the health services in town.

\section{Barriers}

\section{More Information needed at Orientation.}

While some students believed orientation was a facilitator, several students discussed a number of barriers and challenges. One student stated "information that was given through ISA was briefing ... they were more basic stuff." Another student felt that "it would have been more helpful if they could guide us for the first three months on how to use GaurdMe and how it will or will not help us ... [and that] 
international students should be more prepared and informed" when it comes to utilizing medical insurance. Furthermore a student shared that they were unable to make it to orientation and therefore felt at orientation "you cannot give ... information on one day because everyone is going to forget about it, so maybe they need to make it more available to people, like reminders." This particular student suggested that since this information is so important, it should be shared throughout the year, rather than on one day, as information shared in one day may get forgotten about. Another student had a similar experience as they shared "...I know you forget things [that is shared during orientation] after 3 months but you should get back to your student advisor [the ISA members] to remind you what it is again." A different student reflected that "we could work a little more on the orientation part, it would be nice for the students to have more information from the medical staff on campus about little things." Another participant had a similar reflection as they stated "I want the people [ISA] to educate the students and make them be more aware of the healthcare system [by] practically taking them to the clinics or the emergency room." Overall, students felt that orientation lacked information, whether it be about the insurance policies or more information regarding the services in town.

Inefficiency of the Services.

Students felt the stress of long wait times and lack of efficiency when it comes to making healthcare appointments. The participants expressed that they were "expecting more seamless, more efficient, more advanced technology like the apps." Another participant stated "the fact that even if you have a medical emergency and you [still] have to wait is pretty bad [unacceptable]." Another student expressed that they "[had] to wait for an hour and then I got an appointment... another situation was when I had severe back pain for a week... [for that] I have to wait for a long time as well... about 3 to 4 hours." The students mentioned that seeing a doctor in India is much faster than in Canada due to the many private clinics available in India. Another participant had shared a similar feeling, as stated there is an application used in India called "Practo" which allows citizens to make appointments with doctors very easily with very minimal wait time.

\section{Lack of Understanding of Medical Insurance Plans}

Another challenge students expressed was dealing with the expenses with medical insurance. One student expressed frustration when they had to pay an "invoice which went upto $\$ 20,000$ [dollars]" as "GaurdMe did not try to help [me]." When asked as to why they were not covered, the student stated that the insurance company, GaurdMe, needed them to have "...followed the physician's advice." The student however added, that they did get their "...physicians advice well back home." Meaning, this participant had listened appropriately to their physician back in India, but the insurance company needed the student to follow the advice of a Canadian doctor rather than the doctor from India, in order for them to be covered by the insurance policy. Another participant felt that for the amount that MSP costs, there "should be a plan that should cover dental, eye care, and healthcare." Another participant expressed "there are some kind of loopholes which was not clear, particularly eye care and dental which MSP does not cover." Overall students felt that MSP was expensive and that there are loopholes with the insurance policies that students were not aware of, like the lack of eye and dental coverage.

\section{DISCUSSION}

There is considerable amount of research regarding the experience of international students studying abroad. However, there is minimal research around international students' experiences with the healthcare 
system within the country they have migrated too. Therefore this research presents qualitative data that represents several themes regarding the experience of students with the Canadian healthcare system.

\section{Facilitators}

During the interview, students had positive and negative feedback towards the campus orientation. Students stated that the orientation was helpful in understanding what MSP is. Furthermore, campus orientation was also helpful in explaining ways that students were covered by MSP if they were to seek medical attention. Along with understanding what their medical insurance plans are, participants also recall, from orientation, information regarding what to do in an emergent or medical situation, like dialling 911 and where the emergency department is. Overall, the majority of participants appreciated the campus orientation regarding health services as it allowed them to get a better idea of what MSP is. As back in India, health insurance is not mandatory and is therefore not spoken of often, hence coming to Canada, the participants appreciated the information shared at the orientation. These findings relate to Guvendir (2018) and Jones (2013) research whereby international students also had a positive outlook towards orientation, as it gave them the opportunity to learn information about different processes.

Curiosity can play a major role when it comes to learning, which was another common facilitator noted by three participants. Over the centuries, there have been many definitions for curiosity, however a more contemporary definition of curiosity is that it is a form of information seeking that is intrinsic (Kidd \& Hayden, 2015). When asked what was helpful in understanding the healthcare system in Kamloops, these participants stated that mainly their curiosity or their will to ask questions had helped them in understanding the health services in Kamloops. Kidd and Hayden (2015) describe the psychology and science behind curiosity as major motivators when it comes to our learning and decision-making. Furthermore, these participants had also indicated that campus orientation was not as helpful, one of the participants had not even mentioned campus orientation at all. These participants found researching and asking other people questions about the services in Kamloops more helpful than attending orientation. Their curiosity also demonstrated that these participants were more open to asking questions and being sociable which allowed them to gain more information about the services in Kamloops. Therefore with this finding in mind, fostering this aspect of curiosity, as a positive learning tool, during orientation provides students a different way of learning, potentially allowing them to comprehend more information. An example of this is the campus ISA group hosting question and answer sessions strictly regarding healthcare annually for students.

Students found that having a support system, whether it is the ISA members or friends around campus was helpful in understanding the healthcare system better. Such findings are also consistent with the literature for example, Lum, Swartz and Kwan (2016) interviewed immigrant families and discovered that having social supports had assisted these news families into entering the healthcare system. However, the findings from this research adds the perspectives of international students and further presents that having a well established social support system can help even international students in navigating the healthcare system better. An interesting finding from this study, even though all of the eight participants in this research had roommates from India, was that none of them mentioned their room-mates as helpful, in fact one participant mentioned that their room-mate was just as lost as they were when it came to navigating the healthcare system. However, Russell, Thompson, and Rosenthal (2008) presented that Asian international students who had friends on campus were actually more likely to reach out to healthcare services; this was not researched in this study. Therefore continuing to allow students to make appointments with their ISA members raises this idea of maintaining social support. 


\section{Barriers}

Participants stated they appreciated the campus orientation for international students, however there were also some challenges. Many participants had different issues with the campus orientation but a common theme was that orientation lacked practicality, meaning, students wished more information was shared regarding where the services are located and or how to make physician appointments. Higginbottom and Safipour (2015) also point out that one of biggest barriers for immigrated families is the lack of information about the healthcare system, which similarly, is what these participants also felt. Students also suggested that this information is important regarding health and should not be shared in one day. Instead, they suggested that email reminders or year-round information should be shared. In addition to students not being able to recall campus orientation, when six out of the eight students were asked about their priority before coming to Canada, their responses were around housing, food, or school. Health was only a priority for one student, and that was only because they had a pre-existing medical condition. Hence, it is also a possibility that the information shared during orientation, or even orientation as a whole, could have been overlooked, or even forgotten about, due to the many other priorities students are challenged with like food or housing. Educations.com (2019) conducted a survey whereby they demonstrated health as not even one of the major factors when it comes to a priority for studying abroad. The main issues international students look at are regarding housing, ability to work post-graduation, and or quality of the education at the institution (Educations.com, 2019). Since health is just as important as housing and food, universities should promote more information regarding local health care services and how to utilize them.

Long wait times were mentioned as a challenge. Participants reflected that since Canada is a more economically advanced country, they expected it would be more efficient in the delivery of healthcare services. Burgess, McKenzie and Fehr's (2016) study focused more on female international students. The findings from this research were similar as international female students also found the long-wait time frustrating (Burgess, et al., 2016). One participant shared that they were surprised to see the lack of use of the available technology that could be used to improve appointment times. This further demonstrates that even though Canada is more economically advanced than other countries, we are still far behind regarding the utilization of the available technology that could be used to improve the efficiency of our healthcare system. As in India, they are utilizing smartphone applications, like Practo, to make appointments and to decrease the wait times. Zhao et al. (2017) conducted a systematic review whereby they demonstrated that utilizing web-based appointment systems not only decreased wait-times but also decreased staff labour, reduced no-show rates, and improved patient satisfaction. However, shifting towards a more web-based approach in making appointments can also have their limitations. Zhang et al. (2014) present barriers like lack of access to the Internet and low computer skills as challenges patients can face.

Another challenge South Asian international students reported was regarding the health insurance policy. Among the students interviewed, there seemed to have been a pattern whereby participants that had visited a health care professional, stated that they found "loop-holes" within the health insurance policy. Many of the participants did not know that MSP does not cover dental or eye care, and this was a problem for three out of the eight participants, specifically among those that visited a healthcare professional (HCP). The students are however aware of the additional insurance plan that is provided by the student union on campus, whereby all students, domestic and international, are automatically enrolled in the "greenshield plan" which covers dental and eye care. Therefore, it could mostly be a lack of understanding for these students regarding what MSP covers. This lack of understanding of what MSP covers, causes students to 
wait longer to receive treatment or they do not get treatment at all, due to the fact that they are not covered and it is therefore going to be expensive to pay for. Or students receive the treatment or care, but then endup receiving invoices that are too high for them to pay. Similar findings were also presented in Asanin and Wilson's (2008) research, whereby immigrated families also felt that health insurance was expensive and that the insurance should cover dental or eye care and even prescriptions.

Much of the research reported immigrated families have financial challenges with health insurance (Higginbottom \& Safipour, 2015; Mackert et al., 2017). An interesting difference between immigrated individuals and international students in regards to health insurance is that it is mandatory for all international students to be enrolled in a private health insurance before coming to Canada. Since these students are not covered for the first three months by the government issued medical plan, they are then covered by their private insurance. Whereas, immigrated individuals and families are not required to purchase private insurance, and it is their choice, therefore the majority of them tend not to do so, as they find it more expensive (Lum et al., 2016). Overall, little research has been conducted among international students regarding whether they actually understand their insurance, therefore this research provides some insight towards this area.

\section{RECOMMENDATIONS}

We have several recommendations for other similar institutions who recruit South Asian students from their home country. First, the students in this research study recommend that the information shared during orientation about healthcare should be shared throughout the year rather than on one day only. As explained earlier, arriving into a new country and adjusting to all the new changes, it is understandable that some of the information shared during orientation could get missed. Presenting some of the key information on a regular basis through emails or through social media posts like Facebook or Instagram may help students engage and retain more of the important aspects of orientation. Second, during orientation when information is shared regarding healthcare, the focus of this discussion should expand to include not only about how MSP works, but also more details about how to make appointments and how the emergency department works. These details may require consultation with health care professionals in order to ensure accurate information. Mackert et al. (2017) report that during orientation there should be opportunities on how to actually seek and use the health information shared during orientation sessions. For example, scenariobased situations should be presented to the students to solve, as this will allow them to be aware of how to utilize the information that was presented to them. Information that was shared was not sufficient for informing the students about navigating the healthcare system, as issues and confusion were still presented by the students. Last, students suggested having more on-campus services regarding healthcare, whether they be simple blood pressure clinics to information-tables sharing resources that are available on campus or in the community. A potential partnership with one of the universities healthcare facilities like nursing could be created whereby semi-annual health fairs are organized by nursing students for this purpose.

Based on our experience, future research considerations include: (1) conducting research with international students from specific countries and comparing these students experiences with those of this study; (2) focusing research on what the experiences of international students are regarding the Canadian medical insurance plans; and (3) exploring the health or experience of those international students who have a more information-seeking personality/ curious personalities. 
Despite having a smaller sample size and a gender imbalance for this research, this study also lacked a clearer understanding of what international students' knowledge is regarding the medical insurance policies, therefore future researchers should consider including questions regarding knowledge in this area. As English was not their first language, another limitation was the students may not have been able to articulate themselves fully in English. Therefore having an interpreter would have been useful for the interviews, as that would have produced more precise data. Furthermore, instead of a semi-structured interview, structured interviews may have been more beneficial as it would have produced data that was consistent and reliable. As this type of data would have allowed for comparisons to be made more easily from the students answers.

\section{CONCLUSION}

In this study, South Asian international students shed light on their experiences in navigating healthcare services in a small town in British Columbia. Students expressed the facilitators and barriers that have supported and hindered their experiences. They identified campus orientation for international students as a good source of information. Their own curiosity was also seen as another facilitator, as it allowed students to ask questions and be active in their learning. Furthermore, students found that having a social support system is also helpful for navigating the healthcare system. Barriers expressed by the students were that more practical information is needed to help them navigate through healthcare services. Participants also found that our healthcare system was not as efficient, specifically, there are longer wait times in Canada when compared to their home country India. Last, participants demonstrated a lack of knowledge related to "loop-holes" with insurance policies, when really it has to do with a lack of understanding about the insurance policies. Overall this research provides international students' perspective on the Canadian healthcare system and what their facilitators and barriers were regarding how to navigate it. Additionally, our findings reveal insights into how to support new international students when it comes student services regarding health services that is specific to international students. Newly arrived international students are unclear about how the Canadian healthcare system works, therefore as a university, providing as many oncampus resources and opportunities can assist these students to transition well from their home country to Canada.

\section{ACKNOWLEDGEMENT}

This research was supported by the Thompson Rivers University's Undergraduate Research Award Program. I would also like to thank the International Student Advisory group in assisting with recruitment of students and sharing their knowledge regarding Thompson Rivers University's international student's orientation.

\section{Declaration of Interest Statement}

The author reports no conflicts of interest.

\section{Funding}

This work was funded by a grant through Thompson Rivers University's Undergraduate Research Experience Award Program (UREAP) under Inderpreet Kaur Khunkhun.

Inderpreet Khunkhun, a newly graduated $\mathrm{BScN}$ registered nurse and a 2020 graduate from Thompson Rivers University, School of Nursing, Kamloops, British Columbia, Canada. Her research interests continue to develop and will be pursuing a Master's degree in the next 3 years. 


\begin{abstract}
Bonnie Fournier, RN, PhD, is an Associate Professor at Thompson Rivers University, School of Nursing, Kamloops, British Columbia, Canada. Her career has spanned more than 20 years, and includes nursing in areas such as mental health, community health, and global health. Her research is focused on population health interventions utilizing arts-based methods (photovoice, theatre, art, storytelling, dance) to advance health equity.
\end{abstract}

\title{
REFERENCES
}

Akhtar, M., \& Kroner-Herwig, B. (2015). Acculturative stress among international students in context of dociodemographic variables and coping styles. Current Psychology, 34(4), 803-815. doi:10.1007/s12144-015-9303-4.

Asanin, J., \& Wilson, K. (2008). "I spent nine years looking for a doctor": Exploring access to health care among immigrants in Mississauga, Ontario, Canada. Social Science \& Medicine, 66(6), 1271-1283. doi: 10.1016/j.socscimed.2007.11.043

Beaujot, R. (2003). Effect of immigration on the Canadian population: Replacement migration? PSC Discussion Papers Series, 17(3), 1-31.

Beiser, M. (2005). The health of immigrants and refugees in Canada. Canadian Journal of Public Health, 96(S2), 30 44. doi: 10.1007/bf03403701

Braun, V., \& Clarke, V. (2006). Using thematic analysis in psychology. Qualitative Research in Psychology, 3(2), $77-$ 101. doi: 10.1191/1478088706qp063oa

Burgess, K., Mckenzie, W., \& Fehr, F. (2016). International female students' experiences of navigating the Canadian health care system in a small town setting. Intercultural Education, 27(5), 425-436. doi:10.1080/14675986.2016.1240501

Calder, M. J., Richter, S., Mao, Y., Kovacs Burns, K., Mogale, R. S., \& Danko, M. (2016). International students attending Canadian universities: Their experiences with housing, finances, and other issues. Canadian Journal of Higher Education, 46(2), 92-110.

Canadian Bureau for International Education. (2018). Ottawa. Retrieved from http://www.cbie.ca/about-ie/facts-andfigures/

Citizenship and Immigration Canada. (2013). Economic and social objectives of immigration: The evidence that informs immigration levels and education mix. Retrieved from https://www.canada.ca/content/dam/ircc/migration/ircc/english/resources/research/documents/pdf/r33-2013econ-social.pdf

Education.com. (2019). International student affairs. Higher Education Abstracts, 54(1), 43-43. doi: 10.1111/hea.32_12122

Güvendir, M. A. (2018). The relation of an International Student Center's Orientation Training Sessions with international students' achievement and integration to university. Journal of International Students, 8(2), 843860. doi: $10.32674 /$ jis.v8i2.117

Higginbottom, G., \& Safipour, J. (2015). Access to primary health care by new and established immigrants in Canada. Journal of Family Medicine \& Community Health, (5), 1. Retrieved from https://ezproxy.tru.ca/login?url=https://search.ebscohost.com/login.aspx?direct=true\&db=edsswe\&AN=edsswe. oai.DiVA.org.lnu.46354\&site=eds-live

ICEF Monitor. (2019). Canada's foreign student enrolment took another big jump in 2018. Retrieved from https://monitor.icef.com/2019/02/canadas-foreign-student-enrolment-took-another-big-jump-2018/

Immigration, Refugees and Citizenship Canada. (2019). 2018 Annual report. Retrieved from https://www.canada.ca/en/immigration-refugees-citizenship/corporate/publications-manuals/annual-reportparliament-immigration-2018/report.html 
Integrated Planning and Effectiveness. (2018). Thompson Rivers University: Factbook Fiscal Year 2017-18. Retrieved from https://www.tru.ca/_shared/assets/Factbook_2017_201843576.pdf

Jones, K. R., (2013). Developing and implementing a mandatory online student orientation. Online Learning, 17(1). doi: $10.24059 /$ olj.v17i1.312

Kidd, C., \& Hayden, B. Y. (2015). The psychology and neuroscience of curiosity. Neuron, 88(3), 449-460. doi: 10.1016/j.neuron.2015.09.010

Lum, I. D., Swartz, R. H., \& Kwan, M. Y. (2016). Accessibility and use of primary healthcare for immigrants living in the Niagara Region. Social Science \& Medicine,156, 73-79. doi:10.1016/j.socscimed.2016.03.024

Mackert, M., Koh, H., Mabry-Flynn, A., Champlin, S., \& Beal, A. (2017). Domestic and international college students: Health insurance information seeking and use. Journal of International Students, 7(3), 542-561. doi: $10.5281 /$ zenodo. 570016

Maguire, M., \& Delahunt, B. (2017). Doing a thematic analysis: A practical, step-by-step guide for learning and teaching scholars. Retrieved from http://ojs.aishe.org/index.php/aishe-j/article/viewFile/335/553.

Mental Health Commission of Canada. (2019). Immigrant, refugee, ethnocultural and racialized populations and the social determinants of health. Retrieved from https://www.mentalhealthcommission.ca/sites/default/files/201903/irer_report_mar_2019_eng.pdf

Newbold, K. B. (2005). Self-rated health within the Canadian immigrant population: Risk and the healthy immigrant effect. Social Science \& Medicine, 60(6), 1359-1370. doi: 10.1016/j.socscimed.2004.06.048

Presbitero, A. (2016). Culture shock and reverse culture shock: The moderating role of cultural intelligence in international students' adaptation. International Journal of Intercultural Relations, 53, 28-38. https://doiorg.ezproxy.tru.ca/10.1016/j.ijintrel.2016.05.004

Roslyn Kunin \& Associates, Inc. (2018). Economic impact of international education in Canada - 2017 update. Retrieved from https:/www.international.gc.ca/education/report-rapport/impact-2017/index.aspx?lang=eng

Thompson Rivers University. (2018). Medical Insurance. Retrieved from https://www.tru.ca/truworld/newstudents/medical-insurance.html

Thompson Rivers University. (2019). Support Services for International Students. Retrieved from https://www.tru.ca/truworld/future-students/support-services.html

Statistics Canada. (2016). Dependency ratio. Retrieved from https://www150.statcan.gc.ca/n1/pub/82-229x/2009001/demo/dep-eng.htm

Statistics Canada. (2018). Immigration and ethnocultural diversity in Canada. Retrieved from https://www12.statcan.gc.ca/nhs-enm/2011/as-sa/99-010-x/99-010-x2011001-eng.cfm

Zhang, X., Yu, P., \& Yan, J. (2014). Patients' adoption of the e-appointment scheduling service: A case study in primary healthcare. Retrieved from https://www.ncbi.nlm.nih.gov/pubmed/25087546

Zhao, P., Yoo, I., Lavoie, J., Lavoie, B. J., \& Simoes, E. (2017). Web-based medical appointment systems: A systematic review. Journal of Medical Internet Research, 19(4). doi: 10.2196/jmir.6747 